\title{
A Prelab Tutoring System for Strength of Materials Experiment
}

\author{
CHUIN-SHAN CHEN, SHANG-HSIEN HSIEH, SHENG-CHIN CHUANG, SHIU-SHIN LIN \\ Department of Civil Engineering, National Taiwan University, Taipei 10617, Taiwan
}

Received 2 June 2003; accepted 15 December 2003

\begin{abstract}
We aim to resolve a long-standing problem on requiring students to study how to maneuver experiments before they actually conduct them in a laboratory. A prelab tutoring system for the Strength of Materials experiment is prototyped from desired outcomes. The tutoring system utilizes a game-like environment to engage students in learning. Consisting of highly interactive contents made by scalable vector graphics (SVGs), the system helps students to get acquainted with laboratory instruments as well as experimental procedures. The effectiveness and efficiency of the system have been confirmed through a survey among students. (C) 2004 Wiley Periodicals, Inc. Comput Appl Eng Educ 12: 98-105, 2004; Published online in Wiley InterScience (www.interscience.wiley.com); DOI 10.1002/cae.20004
\end{abstract}

Keywords: prelab instruction; computer-aided tutoring system; scalable vector graphics (SVGs); interactive laboratory instruments

\section{INTRODUCTION}

Laboratory courses play a vital role in the engineering mechanics curriculum. Through physical tests, students observe "real" phenomena in their very eyes that reflect theories they have learned. The hands-on experiences not only reinforce students' understanding of theories, but also remind them of the limitations

\footnotetext{
Correspondence to C.-S. Chen (cschen@ @e.ntu.edu.tw).

Contract grant sponsor: The National Science Council; contract grant number: NSC 90-2511-S-002-025.

Contract grant sponsor: The Ministry of Education; contract grant number: E001.

(C) 2004 Wiley Periodicals Inc.
}

of theories. Laboratory, as elegantly described by Sagan [1], differentiates science from psuedoscience and superstition.

In an ideal world, students should have an unlimited access to the laboratory. They could conduct the tests whenever they want. However, limited supplies of laboratory resources, including facilities, equipment, and personnel, put this idealism in jeopardy. Thus, students are often asked to complete a set of experiments in a limited timeframe. For example, a typical laboratory session lasts about 3 to $4 \mathrm{~h}$ in our department. The time constraint motivates the need for prelab assignments [2,3]. Students are asked to study how to maneuver experiments before 
they actually conduct them in a laboratory. In our department, students need to study an instruction manual such as [4] then submit a written report prior to a laboratory session. The static contents of the manual make them difficult to convey the dynamic processes occurred in a laboratory to students. Meanwhile, the lack of real time performance feedback prevents students from correcting their mistakes prior to the experiment.

The ineffectiveness of the traditional prelab activities motivates us to develop a computer-assisted prelab tutoring system for improving the learning environment. In this study, we analyze the requirements for a sound tutoring system and design a desired system based upon the expected outcomes. While prototyping the interactive virtual instruments and laboratory platforms for the system, we demonstrate an effective computer technology using scalable vector graphics (SVGs) [5] to accomplish the tasks.

\section{REQUIREMENT ANALYSIS}

A survey was conducted in our department to understand students' attitude when they were asked to prepare the prelab activities. A group of undergraduate students who had already taken the laboratory courses were evaluated. The results summarized from the 64 samples are:

1. Most students agree that the prelab activities and assignments are necessary. However, $83 \%$ of the students consider the assignments taking too long for them to complete. Moreover, they would like to finish the prelab assignments within $30 \mathrm{~min}$ (Fig. 1a).

2. While writing the prelab report, $75 \%$ of the students had strong inclination to consult those reports written previously by their senior classmates. Only $25 \%$ wrote the prelab report from scratch (Fig. 1b).

3. $85 \%$ of the students consider the traditional prelab activities and assignments ineffective (Fig. 1c).

4. If a computer-aided prelab tutoring system is to be developed, $68 \%$ of the students think that the interactive contents should focus on operating laboratory instruments and experimental procedures (Fig. 1d).

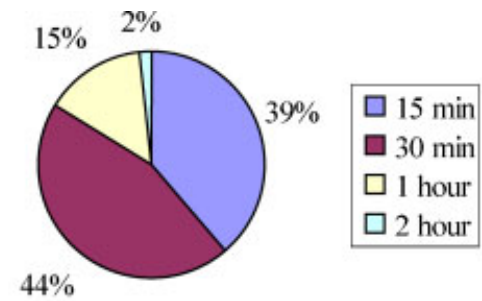

$\mathbf{a}$

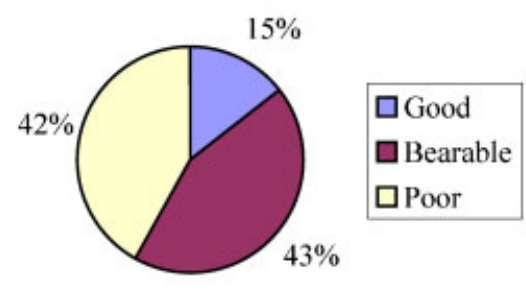

c

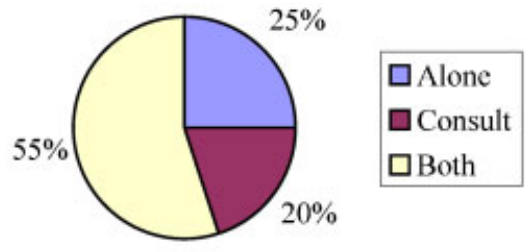

b

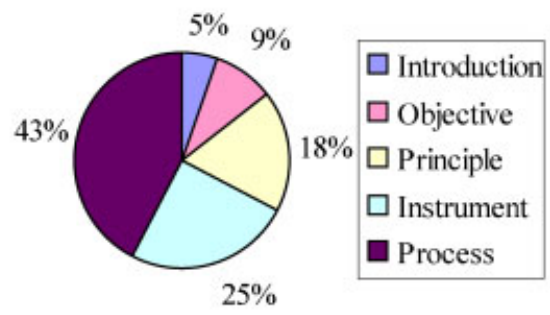

d

Figure 1 Surveying results of students' attitude for preparing the prelab activities; (a) Expected timeframe for preparing prelab activities; (b) Students' attitude while writing prelab report; (c) Effectiveness of traditional prelab practice; (d) Need for multimedia interactive contents. [Color figure can be viewed in the online issue, which is available at www.interscience.wiley.com.] 
From the results of the survey, we write down the following expected outcomes for prototyping the prelab tutoring system:

1. Interaction and enjoyment: Lack of user interaction and feedback is the key drawback of the traditional prelab activities. Unlike static contents described in a traditional instruction manual, multimedia contents can be full of interaction and enjoyment when done correctly [6]. We shall empower the interactive multimedia contents to improve the prelab learning environment.

2. Efficiency and effectiveness: We want our prelab tutoring environment to be efficient and effective. It is efficient so that students will not waste time in writing and/or copying the prelab report, thus can finish the prelab activities within a more satisfactory timeframe. It is effective so that students will learn the prelab materials with assurance of quality.

3. Enhancement and correction: From the survey, students have strong expectation on the tutoring system to deliver highly interactive contents for laboratory instruments and experimental procedures (Fig. 1d). This echoes the learningby-doing methodology that is particularly important for laboratory activities [7]. Highly interactive virtual instruments to enhance laboratory activities and to correct potential operating mistakes should be key ingredients for the prelab tutoring system.

\section{PRELAB TUTORING SYSTEM DEVELOPMENT}

Following Gagne et al. [8], we design the desired prelab tutoring system from its expected outcomes. In this study, the effort is focused on prototyping the prelab tutoring system for materials tensile tests from the Strength of Materials Laboratory course. The contents follow those in the instruction manual [4] and in the textbook by Gere and Timoshenko [9].

\section{Game-Like Environment For Learning Engagement}

A game-like environment is used to engage students in learning. Entering the prelab learning web site, students find the web page shown in Figure 2. It is worth noting that the upper right corner of the figure shows the score and game life of the student engaged. Both features aim to stimulate more learning. The scoring system replaces the traditional grading of the

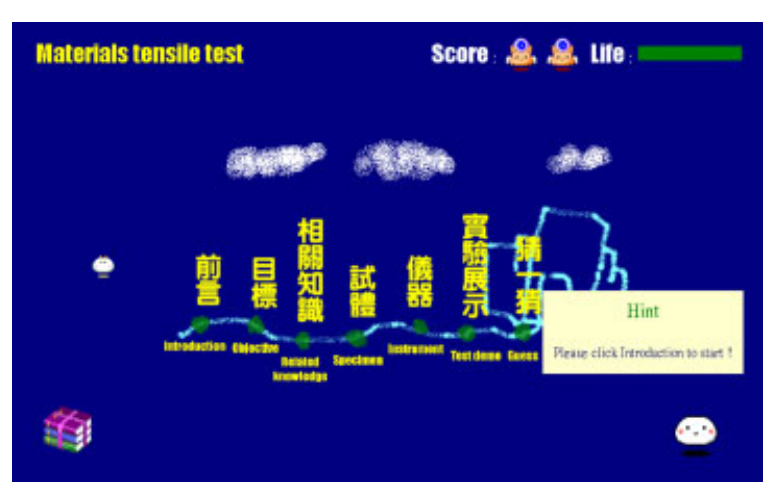

Figure 2 Main page of the prelab tutoring system for materials tensile test. [Color figure can be viewed in the online issue, which is available at www.interscience. wiley.com.]

prelab report by staff. In this environment, students accumulate the score points as learning proceeds. The real time measurement encourages students devoting more efforts to improve their performance. On the other hand, the game life system is used for assuring the quality of students' learning. If the remaining game life drops to zero, the "game" is over and students must restart the prelab activities.

Other features shown in Figure 2 are rather typical. The upper left corner shows the title of the experiment. In the lower right corner, is an on-line tutor providing necessary hints to undertake the prelab activities. The main menu is shown in the middle of the figure with the sessions outlining the overall prelab activities. When students click one of the sessions in the main menu, for example "Instrument," the system will bring up the prelab activities for the selected session as shown in Figure 3.

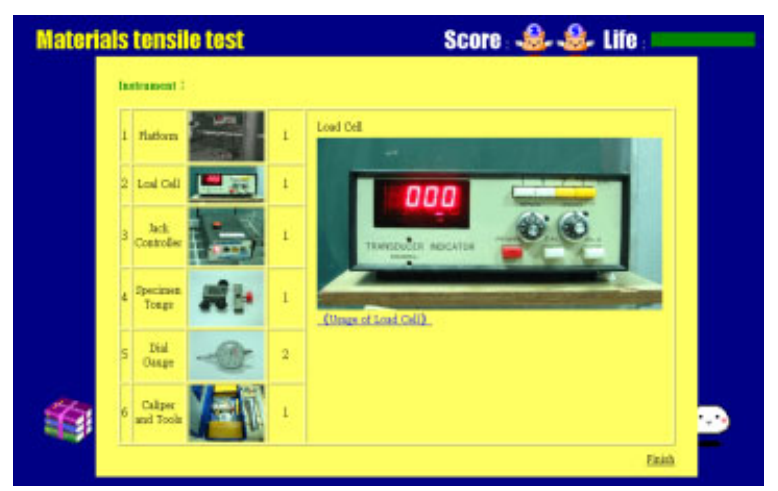

Figure 3 Sample topics for materials tensile testinstrument [Color figure can be viewed in the online issue, which is available at www.interscience.wiley. com.] 


\section{Quizzes For Learning Quality Assurance}

Quizzes are used to assure the learning quality. In our experience as well as others [10], quizzes are the only reliable way to assure students' basic understanding of the assigned materials. Students' quiz performance reflects on both their prelab scores and game life.

A quiz system is embedded in the prelab activities. After students go through the materials covered in a topic (Fig. 3), they click "Finish" to bring up quizzes (Fig. 4). If students submit correct answers for the quizzes, they are not only awarded scores but also granted the permission to move on to the next topic. In case of wrong answers, students receive life reduction penalty and are forced to go through the materials covered in this topic again.

\section{Virtual Instruments For Learning Enhancement}

Interactive virtual laboratory instruments are used to enhance students' comprehension on operating laboratory instruments and on familiarizing with experimental procedures. The virtual instruments integrating with video contents offer versatile learning methodologies, such as learning-by-hearing, learning-by-seeing, and learning-by-doing [7].

In the prototype, five sets of interactive components for the prelab activities of materials tensile tests are developed. These components are:

1. Dial gauge (Fig. 5): A dial gauge is an instrument used to measure length variation of a test specimen. However, how to correctly read the dial gauge is usually not apparent to the novices. Our virtual dial gauge allows students using the mouse to adjust the measuring tip (Fig. 5a), the location of a measured specimen

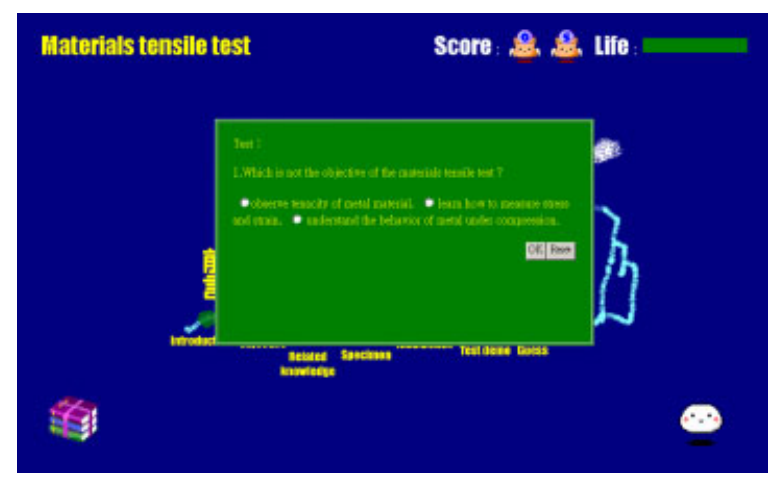

Figure 4 Sample quiz to pass a topic [Color figure can be viewed in the online issue, which is available at www.interscience.wiley.com.]

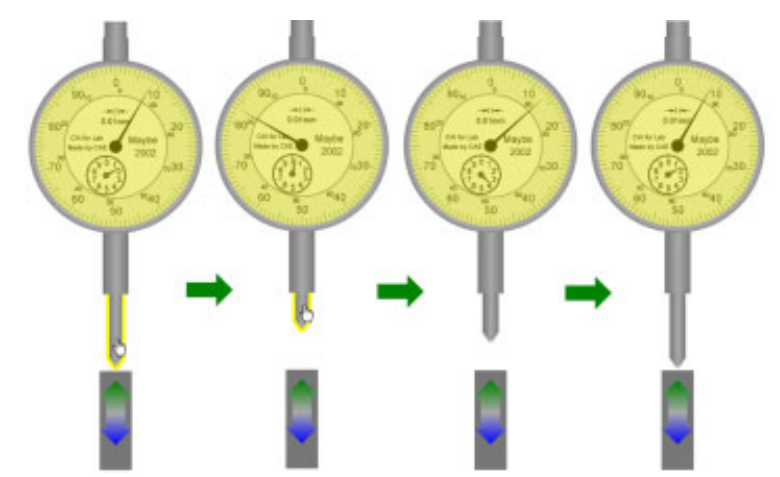

a

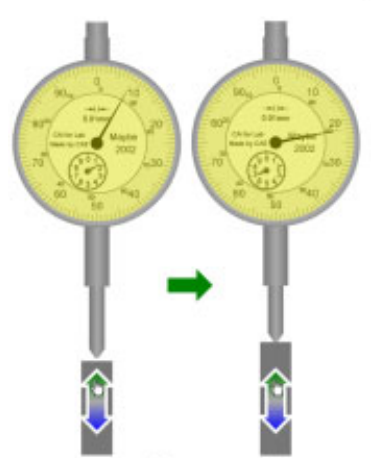

b

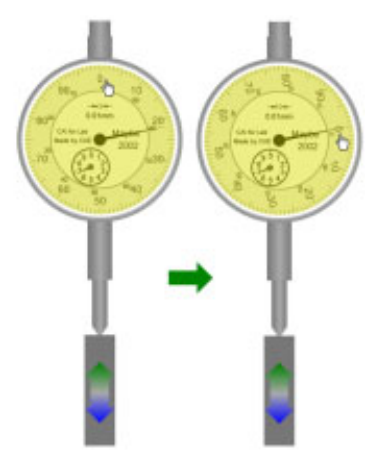

c
Figure 5 Virtual dial gauge; (a) movable measuring tip; (b) movable test specimen; (c) movable reading wheel [Color figure can be viewed in the online issue, which is available at www.interscience.wiley.com.]

(Fig. 5b), and the reading wheel (Fig. 5c). As students adjust these parts, the long and short hands of the dial gauge react accordingly. Such interactions together with a brief technical description help students to get acquainted with the correct way for reading the dial gauge.

2. Load cell (Fig. 6): A load cell is used to measure the magnitude of the load acting on the test specimen. Through the virtual load cell, students can learn the functionality of each button on the cell. Students also learn the procedures of calibrating the load cell reading.

3. Jack controller (Fig. 7): A jack controller is used to control the loading magnitude during

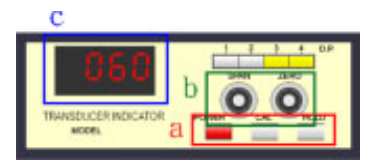

Figure 6 Virtual load cell: (a) buttons for pressing, (b) buttons for rotating, (c) LED reading. [Color figure can be viewed in the online issue, which is available at www.interscience.wiley.com.] 


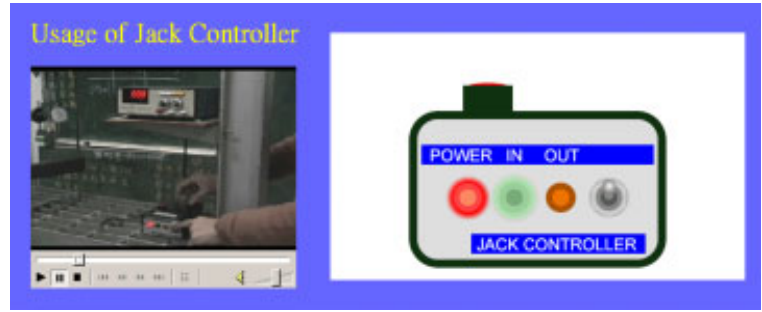

Figure 7 Virtual jack controller. [Color figure can be viewed in the online issue, which is available at www.interscience.wiley.com.]

the materials tensile test. In the virtual controller, students learn how to adjust the loading magnitude through the switch. Students also learn the meanings of light signals on the jack controller.

4. Specimen assembly (Fig. 8): Test specimen assembly involves in coping the specimen with tongs, dial gauges, and bolts. Since the processes require substantial interactions of the parts, it is very difficult to convey the knowledge through a traditional instruction manual. In our virtual laboratory, students can practice the assembly by dragging the parts. Only under a correct sequence and location of placement

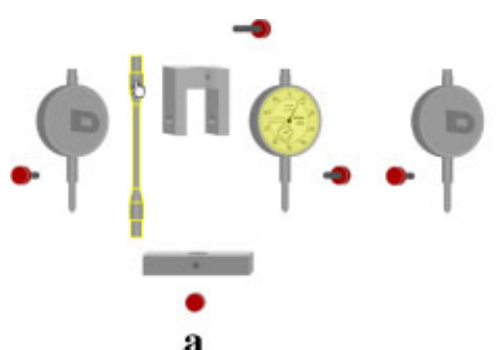

a

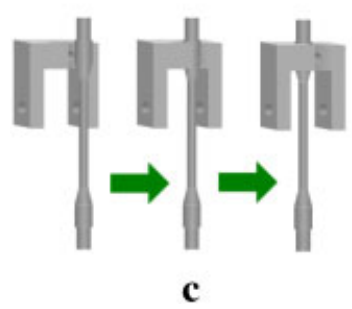

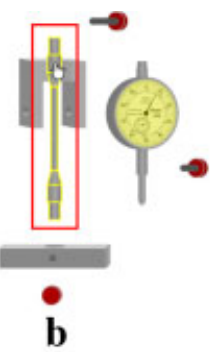

Figure 8 Virtual specimen assembly; (a) drag the specimen; (b) drag to the sensing zone; (c) assemble parts automatically; (d) display final specimen assembly. [Color figure can be viewed in the online issue, which is available at www.interscience.wiley. com.]

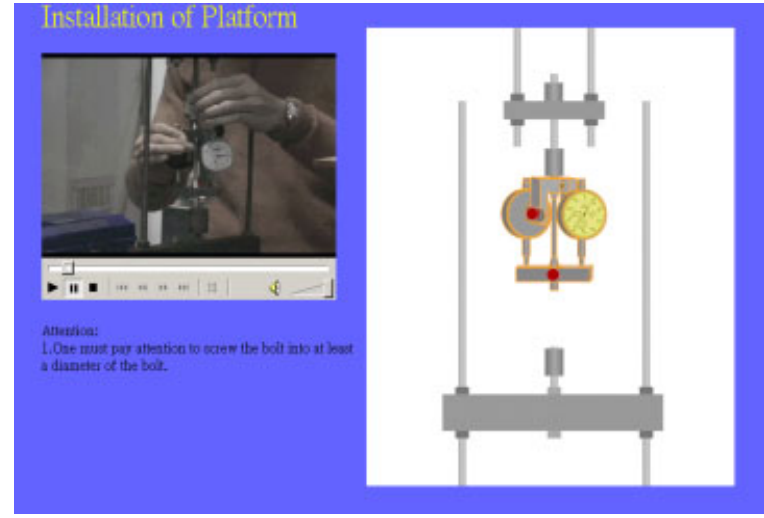

Figure 9 Test platform installation. [Color figure can be viewed in the online issue, which is available at www.interscience.wiley.com.]

will these parts be assembled. Consequently, students learn the important details of test specimen assembly.

5. Platform installation (Fig. 9): When one finishes assembling the specimen, it needs to be installed on the test platform. This set of instruments with video instruction helps students to familiarize with the installation procedures.

\section{VIRTUAL INSTRUMENT IMPLEMENTAION USING SVG}

A wide range of computer technologies can be used to implement the virtual laboratory instruments and experimental procedures. For example, Fang et al. [11] used virtual reality technology to implement a virtual machining laboratory. Students can operate a virtual machine in an immersive environment. Virtual reality based technology provides a highly interactive learning environment, but its relatively high cost limits its general accessibility. Alternatively, Zhu et al. (2001) used 3D modeling technology to construct virtual laboratory instruments for a triaxial test. The virtual instruments were developed using Virtual Reality Markup Language (VRML). The approach, however, suffers from the difficulty of integrating user interactions responsively with virtual instruments.

In this study, SVG is used to implement the virtual laboratory instruments. The major advantages of SVG are its effectiveness in producing interactive graphical objects and in leveraging of other Web standards. SVG utilizes an Extensible Markup Language (XML) grammar to describe 2D graphical objects. In spite of its $2 \mathrm{D}$ description, high quality of 
3D virtual instrument representation can be conveyed in a proper perspective view with shading effects.

SVG graphical objects can be interactive. Mouse event handlers can be easily assigned to the objects. The event handlers and scripting features offer a rich set of interactions that can satisfy our needs. In addition, Adobe System Incorporated has a free SVG viewer plug-in for Microsoft Internet Explorer. Once the viewer is installed, one can easily browse and operate SVG elements in a web page. Below, we briefly describe our implementation using SVG for the virtual dial gauge and specimen assembly.

1. Virtual dial gauge (Fig. 5): in this instrument, the reading wheel, measuring tip, and measured specimen listen to the mouse events. The reading wheel accepts the mouse drag event. When the mouse is moved over the wheel, the wheel will rotate accordingly. The measuring tip also accepts the drag event. When the tip is moved up or down, the long and short hands of the dial gauge will rotate and point to the correct reading. While being relieved, the tip will slowly recover to its original position, as the instrument would react in the real world. Finally, the measured specimen accepts the click event. While clicking on the two-way arrow, one can move the test specimen up or down. The movement of the specimen will press or relieve the measuring tip. One can then observe the subtle changes of the reading in the dial gauge due to the specimen movement.

2. Virtual specimen assembly (Fig. 8): The virtual specimen assembly has its inherent spatial and temporal complexity. The interactions of the parts not only occur in 3D, but also need to obey particular sequences. To manage the complexity, a proper 2D perspective view is first chosen to represent the 3D scenario. A semi-automatic approach is then applied to accomplish the desired functionalities. Users are responsible to drag a part to the assembling zone. The system then performs accurate remaining assembly automatically. In our implementation, the assembling zone is a sensing zone equipped with an attractive force. If a part is dragged and dropped into the zone, it will be sucked into a correct position. Otherwise, the part will move back to its original location. For the sequences of assembly, we make use of activated states of sensing zones to determine whether a zone should accept a particular movement of a part.

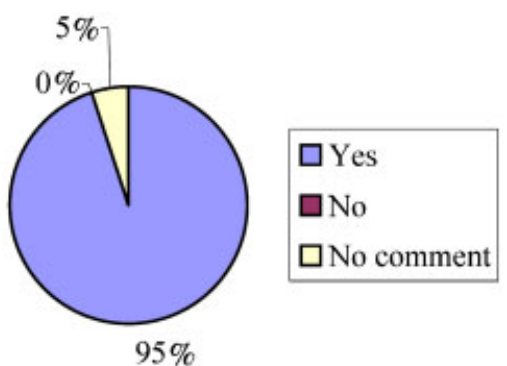

a

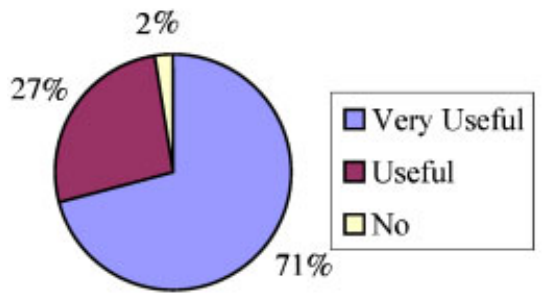

c

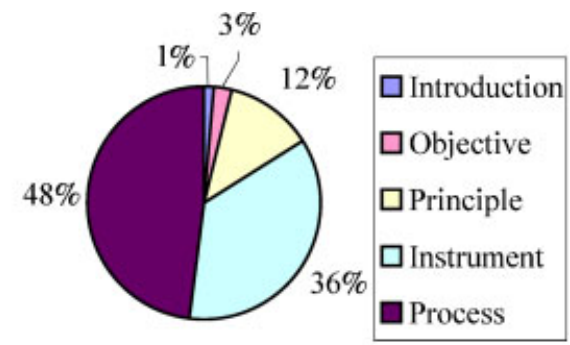

b

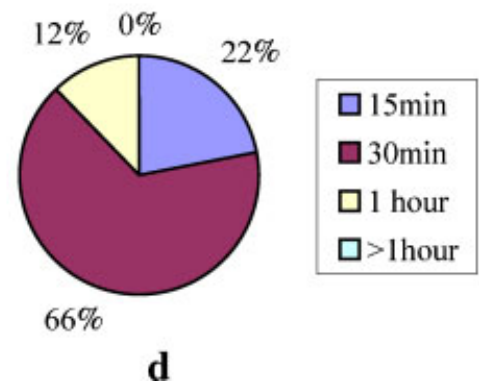

Figure 10 Evaluation survey for the prelab tutoring system; (a) Effectiveness of the system; (b) Most helpful interactive contents; (c) Comprehension for experiments and theories. [Color figure can be viewed in the online issue, which is available at www.interscience.wiley.com.] 


\section{PERFORMANCE EVALUATION}

A survey was conducted when the prototype was completed. $95 \%$ of the students think that using the system for prelab assignments is more effective than the traditional counterparts (Fig. 10a). For the prelab activities, $84 \%$ of the students think that the interactive laboratory instruments and experimental procedures are the most helpful contents (Fig. 10b). With the aid of the tutoring system, $98 \%$ of the students think that they can better comprehend the logical relationship between experiments and theories they have been taught (Fig. 10c). Finally, $88 \%$ of students can finish the assigned prelab activities in $30 \mathrm{~min}$; it proves the efficiency of the system (Fig. 10d).

\section{CONCLUDING REMARKS}

In this study, a prototype of a prelab tutoring system for the Strength of Materials experiment is developed. The system improves upon the traditional prelab activities and delivers the following features:

1. The system makes prelab preparation more efficient. The average time to complete a prelab session takes about $30 \mathrm{~min}$; the timeframe meets most of students' expectation.

2. The system makes prelab activities more effective. Quizzes assure the quality of learning. Real time feedback of interactive contents and answers for the quizzes corrects students' possible mistakes prior to the experiment.

3. The game-like learning environment makes self-study prelab instructions and assignments more stimulating. Comparing with reading the traditional instruction manual, the proposed learning environment delivers much improved prelab activities.

4. The highly interactive contents make operations of laboratory instruments and experimental procedures more comprehensible. In addition, using SVG to implement the interactive contents is an effective mean. The use of SVG also benefits us from coping with other Web standards seamlessly.

\section{ACKNOWLEDGMENTS}

The authors thank Mr. L.-J. Yeh and Mr. A.-B. Chang for their assistance in videoing laboratory experiments.

\section{REFERENCES}

[1] C. Sagan, The demon-haunted world-science as a candle in the dark. Ballantine Books, New York, 1997, pp. 37.

[2] R. M. Powell, H. Anderson, J. van der Spiegel, D. P. Pope, Using web-based technology in laboratory instruction to reduced costs, Comp Appl Eng Educ 10(4) (2002), 204-214.

[3] L. R. Chevalier, J. N. Craddock, P. C. Riley, and B. J. Trunk, Interactive multimedia labware for strength of materials laboratory, Comp Appl Eng Educ 8(1) (2000), 31-37.

[4] Experimentation manual for strength of materials, Department of Civil Engineering, National Taiwan University, Taipei, Taiwan, 1999 (in Chinese).

[5] J. Ferraiolo (Editor), Scalable vector graphics (SVG) 1.0 specification, http://www.w3.org/TR/SVG, W3C recommendation, 2001.

[6] W. W. Lee and D. L. Owens, Multimedia-based instructional design: Computer-based training, WebBased Training, and Distance Learning, Jossey-Bass, 2000.

[7] L. Anido, M. Llamas, and M. J. Fernandez, Labware for the internet, Comp Appl Eng Educ 8(3) 2000, $201-108$.

[8] R. M. Gagne, L. J. Briggs and W. W. Wager, Principles of instructional design, 4th Edition, HBJ College Publishers, 1992, p 39.

[9] J. M. Gere and S. P. Timoshenko, Mechanics of materials, 4th Edition, PWS Publishing Company, USA, 1997.

[10] R. M. Felder and R. Brent, Navigating the bumpy road to student-centered instruction, College Teaching, 44(2) 1996, 43-47.

[11] X. D. Fang, S. Luo, N. J. Lee, and F. Jin, Virtual machining lab for knowledge learning and skills training, Comp Appl Eng Educ 6(2) 1998, 89-97.

[12] G. Zhu, W. Lee, S. Luk, and J. H. Yin, Web-based learning for consolidation settlement analysis and reclamation design, Comp Appl Eng Educ 9(3) 2001, $149-156$. 


\section{BIOGRAPHIES}

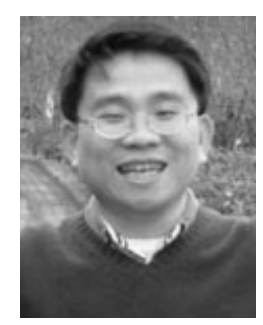

Chuin-Shan Chen graduated from the Department of Civil Engineering at National Taiwan University in Taiwan in 1989 and obtained his $\mathrm{MS}$ and $\mathrm{PhD}$ degrees from the School of Civil and Environmental Engineering at Cornell University in the United States in 1994 and 1999, respectively. From 1999 to 2001, Dr. Chen worked as a postdoc in the School of Civil and Environmental Engineering and as a research associate in the Computational Materials Institute of Cornell Theory Center, both at Cornell University. He is now an assistant professor in the Computer-Aided Engineering Group of the Department of Civil Engineering at National Taiwan University. Dr. Chen's past and present research interests encompass a wide range of subjects; these include multiscale materials modeling, computational fracture mechanics, software development, automation techniques, and elearning. He now devotes most of his time to computational and theoretical aspects of modeling materials and their mechanics interplay across various length and time scales.

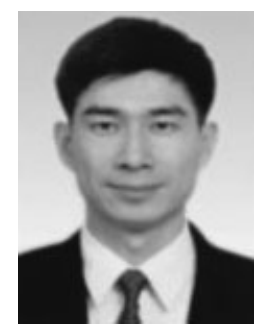

Shang-Hsien Hsieh graduated from the Department of Civil Engineering at National Taiwan University (NTU), Taipei, Taiwan, in 1985 and obtained his MS and PhD degrees from the School of Civil and Environmental Engineering at Cornell University in 1990 and 1993, respectively. From 1993 to 1995,

Dr. Hsieh worked as a postdoctoral research associate in the School of Civil Engineering at Purdue University. He returned to Taiwan and joined NTU in 1995. He is now a professor in the ComputerAided Engineering Group of the Department of Civil Engineering at NTU. Dr. Hsieh has a wide range of research interests, which include parallel and distributed engineering computing, earthquake engineering and structural dynamics, object-oriented software development, engineering information and knowledge management systems, and computer-aided engineering education.

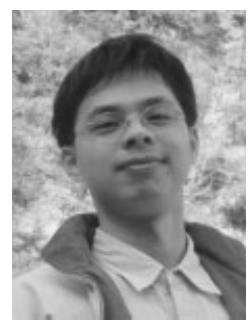

Sheng-Chin Chuang graduated from the Department of Civil Engineering at National Taiwan University (NTU), Taipei, Taiwan, in 2001 and obtained his MS there in 2003. Mr. Chuang's research interests are in scientific visualization and computerassisted instruction.

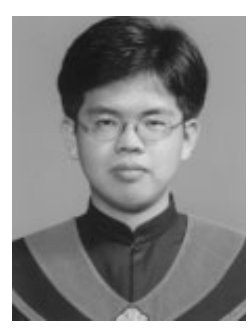

Shiu-Shin Lin graduated from the Department of Hydraulic and Ocean Engineering at National Cheng-Kung University (NCKU), Tainan, Taiwan, in 1997 and obtained his MS degree in 2000. He is a $\mathrm{PhD}$ candidate in the Computer-Aided Engineering Group of the Department of Civil Engineering at National Taiwan University. Mr. Lin's present research interests encompass a wide range of subjects; these include computational hydraulics, object-oriented software development, and artificial intelligence and computational visualization. He now devotes most of his time to computational hydraulics and optimization theory to invest the feasibility of real-time control in Taipei City. 